\title{
Characterization of energy-rich hydrochars from microwave-assisted hydrothermal carbonization of coconut shell
}

Sunday E. Elaigwu ${ }^{1,2 *}$, Gillian M. Greenway ${ }^{1}$

1Department of Chemistry, University of Hull, Cottingham Road, Hull, HU6 7RX, UK

2Department of Chemistry, University of Ilorin, PMB 1515, Ilorin, Kwara State, Nigeria

Corresponding author. Tel. +44 7733680543; fax: +441482466410

E-mail addresses: S.E.Elaigwu@2009.hull.ac.uk; sunnietrinex@hotmail.com

\begin{abstract}
In this study, microwave-assisted hydrothermal carbonization of waste coconut shell (feedstock) is reported. It is a thermo-conversion technique in which the feedstock was transformed into energy-rich carbonaceous material under mild conditions. The process was conducted in a microwave oven by heating the waste coconut shell in deionized water inside a pressurized vessel. The effects of different process conditions on the product yields, and the energy properties of the hydrochars were studied by varying the reaction temperature from 150 $200{ }^{\circ} \mathrm{C}$ and residence time from $5-30 \mathrm{~min}$. The results showed that there was transformation of the feedstock in the process due to the decarboxylation, dehydration, and demethanation reactions. This led to changes in the chemical and structural compositions, as well as increase in the energy properties of the prepared hydrochars. The higher heating value increased from $15.06 \mathrm{MJ} / \mathrm{Kg}$ in the feedstock to $19.76 \mathrm{MJ} / \mathrm{Kg}$ in the hydrochar. The energy properties of the hydrochars prepared in this study showed that microwave-assisted hydrothermal carbonization process could be a technique for converting waste coconut shell into high value-added product.
\end{abstract}

Keywords: Microwave-assisted, hydrothermal carbonization, hydrochar, coconut shell, product yields, energy properties 
This is a post-peer-review, pre-copyedit version of an article published in Waste and Biomass Valorization.. The final authenticated version is available online at: $h$ ttps://doi.org/10.1007/s12649-018-0209-x

\section{Introduction}

Increase in demand for energy worldwide has raised global anxiety due to the depletion of fossil fuel, which may not be enough for the sustainability of this demand in the near future [1]. Concerns about the environment impact of fossil fuel also exist. As a result, research to develop a more environmental friendly fuel technology for the conversion of readily available and renewable feedstocks, such as lignocellulosic biomass to renewable fuels to serve as an alternative to fossil fuel has been on the increase in recent time [2]. Many of these researches have shown new chemical and thermochemical routes. Therefore, different techniques have been established, and utilized in the conversion of these renewable feedstocks into renewable fuels [3].

Hydrothermal carbonization is one of such techniques for the conversion of renewable feedstocks to fuels. It is a simple, promising, low-cost and attractive green thermal process, which is carried out by heating the feedstock in water under pressure at a temperature of $150-350{ }^{\circ} \mathrm{C}$ to produce solid carbonaceous material known as hydrochar, and water soluble organics [4,5]. During the process different kinds of reaction such as dehydration, hydrolysis, condensation polymerization, decarboxylation and aromatization usually takes place. The technique has advantage over other techniques of carbonization such as pyrolysis and gasification, because of its simple procedure, mild reaction environment, and the ability to use wet feedstocks without the initial drying process as observed in other carbonization processes [6]. The hydrothermal carbonization process can be carried out either by using conventional or microwave heating [4].

In many chemical processes, the use of microwave technology has proved to be an effective energy process when compared with the conventional methods of heating. This is because, it has the potential of overcoming the drawbacks of the conventional methods of heating such as, non-selective heating, long residence times, and non-homogenous heating, and thus provides fast, selective and homogenous heating, which appreciably cut down on the processing cost and time [7]. The use of microwave heating in the hydrothermal carbonization of 
biomass materials is not new; it has been previously reported by different researchers and also within our group [4, 6-9].

Coconut (Cocos nucifera) is a tree that is found in large quantities in tropical and subtropical countries of the world. It belongs to the family of Arecaceae and at present has many domestic, commercial and industrial uses [10]. The shell is the strongest part that covers fruit and also one of the waste products obtained from its numerous uses. It is readily available and has been extensively studied in carbon science [10]. The carbonization of coconut shell for use as activated carbons has been reported at various times by different research groups worldwide and a lot of literatures are available on it [11-13]. However, no previous study has reported the microwave-assisted hydrothermal carbonization and the energy properties of the hydrochar from the coconut shell to the best of our knowledge. The conversion of coconut shell into energy-rich hydrochar will serve the purposes of managing the waste material thereby solving environmental problem, and also converting it into useful value-added material.

The aim of this study was to use an environmental friendly procedure to process waste coconut shell into a form that will produce a valuable energy-rich end product. Therefore, in this study, microwave-assisted hydrothermal carbonization technological approach of converting coconut shell into energyrich hydrochar is reported. The effect of different process conditions, such as reaction temperatures and residence time on the product yields and the energy properties of the prepared hydrochars was studied. The chemical and structural characterization, and the thermal stability of the prepared hydrochar were also carried out.

\section{Materials and methods}

\subsection{Materials}

The coconut shell was obtained in Hull, United Kingdom from coconuts purchased from Tesco supermarket. It was washed, dried, crushed and sieved to $2 \mathrm{~mm}$ particle size. It was stored in a dessicator and subsequently used in the preparation of the hydrochars. 
This is a post-peer-review, pre-copyedit version of an article published in Waste and Biomass Valorization.. The final authenticated version is available online at: $h$ ttps://doi.org/10.1007/s12649-018-0209-x

\subsection{Methods}

The experiment was carried out in a microwave oven (MARS, CEM, Milton Keynes, United Kingdom equipped with XP1500 digestion vessels shown in Fig. 1) at $2.45 \mathrm{GHz}$, and $1600 \mathrm{~W}$. An infrared fibre optic sensor fitted into the ceramic sleeve of the reference vessel was used to monitor the reaction temperature, while a pressure sensor fitted into the same reference vessel was used to monitor the reaction pressure $[4,6,7,14]$.

\section{Fig. 1}

The experimental procedure was as described in our previous studies $[4,6,7,14]$, and it is described briefly as follows. $2 \mathrm{~g}$ each of the $2 \mathrm{~mm}$ sized coconut shell were weighed into different reaction vessels $(100 \mathrm{~mL})$ made of Teflon. This was followed by the addition of $30 \mathrm{~mL}$ de-ionized water. The vessels were closed and placed in the microwave oven set to rise to a specified temperature in $5 \mathrm{~min}$. The hydrothermal carbonization was then carried out between $150-200{ }^{\circ} \mathrm{C}$ in for 5 $30 \mathrm{~min}$. At the completion of the hydrothermal carbonization process, the vessels were left to cool down to room temperature. Whatman filter paper number 3 , ashless $11 \mathrm{~cm}$ was used to filter off the hydrochar (carbonized material). Washing of the obtained hydrochar was then carried out numerous times with de-ionized water until a neutral $\mathrm{pH}$ was obtained. Thereafter, it was dried in a conventional oven at $80{ }^{\circ} \mathrm{C}$ for $16 \mathrm{~h}$. The prepared hydrochars were denoted as CSHx-y, where $x$ represents the reaction temperature $\left({ }^{\circ} \mathrm{C}\right)$, and y the residence time (min).

\subsection{Characterization techniques}

Characterization of the hydrochars was carried out using a wide range of instruments. Elemental (CHN) analysis was performed on a Fisons instruments (EA 1108 CHN analyzer), Crawley, UK. Prior to the analysis, the samples were made into fine powder, which was weighed into tin capsules, before being placed on the autosampler for analysis. Thermoscientific Nicolet 380 FTIR (Themo Scientific, Hemel Hempstead, UK), fitted with an attenuated total reflectance (ATR) was used for the FTIR study. The investigation was performed in the wavenumber range of $4000-525 \mathrm{~cm}^{-1}$ using 16 scans at a spectral resolution 
wavenumber of $4 \mathrm{~cm}^{-1}$. SEM analysis was conducted on a ZEISS EVO 60 SEM (Carl Zeiss, Cambridge, UK); before analysis the samples were pre-treated by coating with gold and platinum alloy and were impregnated on a sticky disc. Micromeritics Tristar BET- $\mathrm{N}_{2}$ surface area analyzer was used for the surface area analysis. Prior to the surface area analysis, the samples were degassed under nitrogen at $120{ }^{\circ} \mathrm{C}$ for $3 \mathrm{~h}$. Thermogravimetic analysis (TGA) and differential thermogravimetry (DTG) were obtained using a Mettler Toledo-TGA/DSC 1 instrument under nitrogen $\left(\mathrm{N}_{2}\right)$ atmosphere at a heating rate of $30{ }^{\circ} \mathrm{C} \mathrm{min}^{-1}$.

\subsection{Ash content determination}

The determination of the $\mathrm{pH}$ was based on our previously method [7]. $2 \mathrm{~g}$ of dried hydrochar was weighed into a ceramic crucible of known weight. The crucible and its content were then dried at $80{ }^{\circ} \mathrm{C}$ for $16 \mathrm{~h}$ and reweighed to obtain the dry weight of the hydrochar. The hydrochar and the crucible were then heated in a furnace at $760{ }^{\circ} \mathrm{C}$ for $6 \mathrm{~h}$. After which the crucible and its content were cooled in a desiccator and reweighed. The ash content of the hydrochar was then calculated as follows:

$$
\text { Ash content }(\%)=\frac{\text { Remaining weight of hydrochar }(g)}{\text { Original weight of hydrochar }(g)} \times 100
$$

\section{$2.5 \mathrm{pH}$ determination}

The determination of the $\mathrm{pH}$ was based on our previously method [7]. Suspension of hydrochar in deionized water $[1 \%(\mathrm{wt} / \mathrm{wt})]$ was prepared, and the $\mathrm{pH}$ was measured using a FisherBrand Hydrus $500 \mathrm{pH}$ meter (Fisher Scientific, Loughborough, UK) that has been calibrated using buffer solutions ( $\mathrm{pH}$ 4 and $\mathrm{pH}$ 7). Recalibration of the $\mathrm{pH}$ meter was performed after every five analyses, if the $\mathrm{pH}$ of the $\mathrm{pH} 7$ buffer varies in by more than $\pm 0.1 \mathrm{pH}$ units.

\subsection{Product yield (\%)}

The product yield was calculated from the dried weights of the hydrochar and the feedstock according to the following equation: 


$$
\text { Product yield }(\%)=\frac{\text { Weight of hydrochar }(\mathrm{g})}{\text { Weight of feedstock }(\mathrm{g})} \times 100
$$

\subsection{Energy properties of the hydrochars}

The higher heating value (HHV), energy densification ratio, and energy yield were calculated using the following equations as reported in our previous study [4]

$$
\begin{gathered}
H H V=0.3383(+1.422(\mathrm{H}-0 / 8) \quad \text { (Dulong's formula) } \\
\text { Energy densntification ratio }=\frac{H H V \text { of hydrochar }}{H H V \text { of feedstock }}
\end{gathered}
$$

Energy yield $(\%)=$ Product yield $\times$ Energy densification ratio

The experiments were performed in triplicate, and the results are summarized in Table 1.

\section{Results and discussion}

\subsection{Elemental analysis, ash and pH contents}

The carbon, hydrogen and nitrogen (CHN) compositions of the feedstock and hydrochars are shown in Table 1 . As the reaction temperature and residence time were increased, the carbon content increased in the hydrochar, while the hydrogen and oxygen contents reduced. This observed trend is consistent with behaviour of lignocellulosic biomass during hydrothermal carbonization process $[4,7]$. It has been attributed to the different reactions such as, dehydration, deoxygenating and decarboxylation reactions that occurred during the hydrothermal carbonization process [15-18].

The ash content of the hydrochars (Table 1) increased with increase in the reaction temperature and residence time. This observed trend could probably be as a result of precipitation of minerals in the ash as the temperature of the water was increased, and some inorganics may also have been deposited on the hydrochar during the hydrothermal process [19]. Although, Funke and Ziegler 
[20] reported that the actual behaviour of inorganics during hydrothermal carbonization process is not very clear. Recent studies however, reported that inorganics were well removed from lignocellulosic biomass after hydrothermal carbonization process $[7,21]$. The acidic $\mathrm{pH}$ values displayed by the hydrochars is due to formation of water soluble organic acids during the hydrothermal carbonization process, as well as their high oxygenated functional groups, which is consistent with previous studies $[4,14]$.

\section{Table 1}

The atomic ratios of $\mathrm{O} / \mathrm{C}$ and $\mathrm{H} / \mathrm{C}$ decreased respectively from 0.77 and 1.40 in the feedstock to 0.54 and 1.25 in $\mathrm{CSH}_{200-30}$ as the reaction temperature, and residence time for the carbonization process were increased. This is mostly linked to the different reactions that occurred during the microwave-assisted hydrothermal carbonization process such as, decarboxylation, dehydration, and demethanation reactions $[16,19]$. In other to study the evolution of these atomic compositions, van Krevelen diagram (graph of $\mathrm{H} / \mathrm{C}$ against $\mathrm{O} / \mathrm{C}$ atomic ratios) for the feedstock and hydrochar samples was plotted as shown in Fig. 2. It is valuable way to show the effects of reaction temperature and residence time on the hydrothermal carbonization process, and also vital in the assessment of the energy quality of the solid fuel [22]. The $\mathrm{O} / \mathrm{C}$ and $\mathrm{H} / \mathrm{C}$ atomic ratios fell in the biomass region for the feedstock, while it fell in the peat and lignite region of a typical van Krevelen diagram for the hydrochars [4,23].

\section{Fig. 2}

\subsection{Product yields}

The effect of reaction temperature and residence time on the yields of the hydrochars is presented in Fig. 3. In contrast to our previous studies [4,7], the coconut shell used as feedstock in this study presents an opposite behaviour. The hydrochar yields increased as the reaction temperature and residence time were increased. The increase in product yield with time is consistent with the observed trend during the microwave-assisted hydrothermal carbonization of pine sawdust (Pinus sp.) [8]. Although, the increase in product yield with temperature in this study is inconsistent with previous studies using biomass as 
feedstock, it is in agreement with the observed trend during the hydrothermal carbonization of glucose in saline water [24]. The amount of volatile compounds in the coconut shell could probably be higher than that of the Prosopis africana shell and rapeseed husk used in our previous studies due to its high concentration of lignin and hemicelluloses. Side reactions between the surface of the hydrochars formed, and these volatile compounds released from the degradation of the coconut shell during the microwave-assisted hydrothermal carbonization process could have resulted in the increase in the product yield with reaction temperature and residence time $[8,25]$.

Liu et al. [26] reported that a higher percentage of the solid product can be obtained at temperatures of about $200{ }^{\circ} \mathrm{C}$, and as the temperature is increased above $200{ }^{\circ} \mathrm{C}$ to $250{ }^{\circ} \mathrm{C}$, a lower yield of solid product will be obtained. Temperature of $200-400{ }^{\circ} \mathrm{C}$ has been reported as the temperature in which the main decomposition of lignocellulosic biomass occur during pyrolysis process [11]. Thus, the observed trends in this study could be attributed to the chemical nature of the feedstock, and the reaction temperatures used.

Fig. 3

\subsection{Energy properties}

\subsubsection{Higher heating value}

The higher heating value (HHV) is an important feature of the biomass and hydrochars as it indicates the total quantity of energy stored in the material. The HHVs calculated in this study for the hydrochars (Table 1) increased with increase in reaction temperature and residence time from $16.77 \mathrm{MJ} / \mathrm{kg}$ at $150{ }^{\circ} \mathrm{C}$ for $20 \mathrm{~min}$ to $19.76 \mathrm{MJ} / \mathrm{kg}$ at $200{ }^{\circ} \mathrm{C}$ for $30 \mathrm{~min}$. This is in agreement with previous reports, that increase in reaction temperature and residence time has a direct effect on energy content of hydrochar due to the decrease in oxygen contents and the increase in carbon contents during the hydrothermal process $[4,7,27]$. The HHVs in this study were similar to that of our previous study using rapeseed husk [4]. In this study, the highest HHV value revealed an increase of $31.21 \%$ vis-a-vis that of the feedstock, which is higher than the $21 \%$ hitherto reported for dry leaves [27]. 


\subsubsection{Energy densification}

During the hydrothermal carbonization process of biomass, different kinds of reactions such as, dehydration, decarboxylation, and condensation usually take place leading to the carbonization of the feedstock $[4,6,7]$. This also results in energy densification (ED) that is used to evaluate the success of the hydrothermal carbonization process [28]. The ED ratios (Table 1) of the hydrochars increased with reaction temperature and residence time, and ranged from 1.11-1.31, which is within the previously reported range $[4,7,29]$.

\subsubsection{Energy yield}

The energy yields (EY) of the hydrochars are shown in Table 1. The lowest energy yield of $64.58 \%$ was found when the reaction temperature and residence time were $150{ }^{\circ} \mathrm{C}$ and 20 min respectively. This is expected as reaction temperature of $150{ }^{\circ} \mathrm{C}$ has been reported as the lower temperature during the hydrothermal carbonization process that the components of woody materials start degrading [4,27]. The EY yield of the hydrochars increased gradually until the highest value of $85.28 \%$ was obtained after $30 \mathrm{~min}$ at $200{ }^{\circ} \mathrm{C}$. The observed trend in this study is inconsistent with previous report that the EY of hydrochars decrease with increase temperature [30]. This could probably be due to difference in the hydrothermal conditions and the chemical nature of feedstock [19].

\subsection{Chemical and structural characterization}

For conciseness, the chemical and structural characterization will be limited to the hydrochar prepared at $200{ }^{\circ} \mathrm{C}$ for $30 \mathrm{~min}\left(\mathrm{CSH}_{200-30}\right)$ that has the maximum values for the energy properties and product yield.

\subsubsection{FT-IR analysis}

FTIR spectra of the feedstock and hydrochar shown in Fig. 4 gave additional information on the chemical nature of the feedstock and hydrochar. The classification into the different sections for the functional groups was based on previous studies [31,32] and summarized in Table 2. The presence of single bond functional groups, viz. $\mathrm{C}-\mathrm{H}, \mathrm{C}-\mathrm{O}$, and $\mathrm{O}-\mathrm{H}$ was anticipated. This is because the 
coconut shell used as feedstock in this study is a lignocellulosic biomass that is made up of lignin, cellulose, and hemicelluloses [33]. Lignin presence in the feedstock is revealed by the peaks in Sections 3 and 4 ( $C=0$ and $C=C$ bonds) [31]. These peaks remained in the hydrochar although with less intensity after the carbonization process, which illustrates the presence of lignin fragments and intermediate structures [10]. This observation proves that lignin did not completely breakdown under the conditions studied [30]. The weak intensity of the FT-IR spectrum of the hydrochar in comparison with that of the feedstock provided an evidence, that the different reaction such as deoxygenating, decarboxylation, and dehydration that occurred during the microwave-assisted hydrothermal carbonization process, led to the decomposition of the functional groups on the coconut shell [30]. The result obtained in this study is consistent with our previous studies $[4,7]$.

\section{Fig. 4}

\subsubsection{Thermal stability of the hydrochar}

Fig. 5 shows the thermogravimetric analysis (TGA) and differential thermogravimetry (DTG) profiles of the thermal behaviour of the hydrochar. As with other previous studies $[4,7,28,34]$, three major stages of weight loss were found in the TGA curve. The first stage which occurred at temperature $<250{ }^{\circ} \mathrm{C}$, is usually ascribed to the removal of moisture and release of volatile compounds from the hydrochar $[28,34]$. The weight loss in the second stage that occurred between the temperatures of $250-400{ }^{\circ} \mathrm{C}$ is attributed to hemicellulose and cellulose decomposition, in which chemical bonds are broken and volatiles compounds are formed [34]. The third stage and final stage of weight loss occurred at $400-650{ }^{\circ} \mathrm{C}$. This weight loss stage is ascribed to lignin decomposition, the most recalcitrant among the components of lignocelloulosic biomass to be decomposed. The decomposition of lignin usually occurs gradually throughout the whole temperature range used due to its complex structure $[35,36]$. On the other hand, three peaks were also observed in the DTG curve derived from the TGA profile of the hydrochar. The first, which is a small peak, was found in the temperature range of $50-100{ }^{\circ} \mathrm{C}$ (drying region). This peak 
could be attributed to the dehydration of the hydrochar [11]. The second peak occurred between 300 and $350{ }^{\circ} \mathrm{C}$. This peak is long and sharp, and can be ascribed to hemicellulose and cellulose degradation [37]. The nature of this peak implies that the weight loss in the hydrochar could mainly be associated with its high cellulose and hemicellulose contents after the drying process [34]. The third peak is in the temperature range of $450-680{ }^{\circ} \mathrm{C}$. This broad peak is usually attributed to the thermal decay of lignin and other high molecular mass molecules $[37,38]$.

\section{Fig. 5}

\subsubsection{SEM analysis}

The scanning electron microscopy (SEM) was used to examine the structural morphologies of the feedstock and hydrochar, and the images are shown in Fig. 6. The morphology of the hydrochar is made up of collections of 1-10 $\mu \mathrm{m}$ spherelike microparticles that are coarse, while that of the feedstock revealed a cellular structure. This observed difference showed that during the microwave-assisted hydrothermal carbonization process the feedstock underwent some changes. This is not unexpected, as it is already known that under the microwave heating transformation of the feedstock will occur. The collections of the sphere-like microparticles seen on the hydrochar are from breakdown of cellulose [15], while the coarse surface of the microparticles is derived from the remaining lignin in the hydrochar. The complex nature of lignin and its high thermal stability made it difficult for it to be completely degraded during the hydrothermal carbonization process [28].

\section{Fig. 6}

\subsubsection{Nitrogen adsorption measurement}

A plot of the nitrogen adsorption measurement shown in Fig. 7 displayed a typical Type II isotherm, according to the IUPAC classification system. Nonporous materials usually display this type of isotherm [39]. Thus, the BET surface area of the hydrochar is relatively small owing to the lack of porosity in the hydrochar. In this kind of situation, the obtained surface area relates only to 
the external surface [40]. During the hydrothermal carbonization process, carbonization of the feedstock occurs in addition to solubilization of the organics formed, which leads to the formation of tarry substances $[7,10]$. These tarry substances contaminate the hydrochar by blocking the pores, thus making the measured BET surface area small [41]. Consequently, for the hydrochar to fit into certain uses, such as, hydrogen or electrical energy storage, there is a need to improve the porosity and the surface area of hydrochar [28].

\section{Fig. 7}

\section{Conclusion}

In this study, microwave-assisted hydrothermal carbonization process of coconut shell is reported. It was carried out by varying the reaction temperature from $150-200{ }^{\circ} \mathrm{C}$ and residence time from 5-30 min. The decomposition of the feedstock during the process led to changes in its elemental compositions, which resulted in an increase in the heating value of the hydrochars. This changes was confirmed by the chemical and structural and characterization carried out. At the highest reaction temperature and residence time, the higher heating values (HHV) of the hydrochars increased by about $18 \%$ and $9 \%$ respectively. The energy yields also increased with increase in reaction temperature and residence time. The results of this study showed that the hydrochars produced from the microwave-assisted hydrothermal carbonization of coconut shell are rich in energy, and thus have solid fuel potentials.

\section{Acknowledgements}

The authors wish to thank Petroleum Technology Development Fund (PTDF), Nigeria for the PhD studentship of Dr. Sunday E. Elaigwu. We also wish to thank Bob Knight of the Department of Chemistry, University of Hull for his assistance with CEM microwave oven.

\section{References}

[1] Asomaning, J., Mussone, P., Bressler, DC.: Two-stage thermal conversion of inedible lipid feedstocks to renewable chemicals and fuels. Bioresour. Technol. $158,55-62(2014)$ 
[2] Maher, K.D., Bressler, D.C.: Pyrolysis of triglyceride materials for the production of renewable fuels and chemicals. Bioresour. Technol. 98, 2351-2368 (2007)

[3] Asomaning, J., Mussone, P., Bressler, D.C.: Pyrolysis of polyunsaturated fatty acids. Fuel Process Technol. 120, 89-95 (2014)

[4] Elaigwu, S.E., Greenway, G.M.: Microwave-assisted hydrothermal carbonization of rapeseed husk: A strategy for improving its solid fuel properties. Fuel Process Technol. 149, 305-312 (2016)

[5] Liu, F., Gao, M.: Comparison of the characteristics of hydrothermal carbons derived from holocellulose and crude biomass. J. Mater. Sci. 50, 1624-1631 (2015)

[6] Elaigwu, S.E., Greenway, G.M.: Chemical, structural and energy properties of hydrochars from microwave-assisted hydrothermal carbonization of glucose. Int. J. Ind. Chem. 7, 449-456 (2016)

[7] Elaigwu, S.E., Greenway, G.M.: Microwave-assisted and conventional hydrothermal carbonization of lignocellulosic waste material: comparison of the chemical and structural properties of the hydrochars. J. Anal. Appl. Pyrol. 118, 18 (2016)

[8] Guiotoku, M., Rambo, C.R., Hansel, F.A., Magalhaes, WLE, Hotza, D.: Microwave-assisted hydrothermal carbonization of lignocellulosic materials. Mater. Lett. 63, 2707-2709 (2009)

[9] Li, M.F., Shen, Y., Sun, J.K., Bian, J., Chen, C.Z., Sun, R.C.: Wet Torrefaction of bamboo in hydrochloric acid solution by microwave heating. ACS Sustain. Chem. Eng. 3, 2022-2029 (2015)

[10] Elaigwu, S.E.: Pollution Reduction With Processed Waste Materials (PhD Thesis) Department of Chemistry, University of Hull, United Kingdom, 2013.

[11] Li, W., Yang, K., Peng, J., Zhang, L., Guo, S., Xia, H.: Effects of carbonization temperatures on characteristics of porosity in coconut shell chars and activated carbons derived from carbonized coconut shell chars. Ind. Crop Prod. 28, 190- 
This is a post-peer-review, pre-copyedit version of an article published in Waste and Biomass Valorization.. The final authenticated version is available online at: $h$ ttps://doi.org/10.1007/s12649-018-0209-x

$198(2008)$

[12] Yang, K., Peng, J., Srinivasakannan, C., Zhang, L., Xia, H., Duan, X.: Preparation of high surface area activated carbon from coconut shell using microwave heating. Bioresour. Technol. 101, 6163-6169 (2010)

[13] Hu, Z., Srinivasan, M.P.: Preparation of high-surface-area activated carbons from coconut shell. Micropor. Mesopor. Mat. 27, 11-18 (1999)

[14] Elaigwu, S.E., Rocher, V., Kyriakou, G., Greenway, G.M.: Removal of $\mathrm{Pb}^{2+}$ and $\mathrm{Cd}^{2+}$ from aqueous solution using chars from pyrolysis and microwave-assisted hydro- thermal carbonization of Prosopis africana shell. J. Ind. Eng. Chem. 20, $3467-3473$ (2014)

[15] Sevilla, M., Macia-Agullo, J.A., Fuertes, A.B.: Hydrothermal carbonization of biomass as a route for the sequestration of $\mathrm{CO}_{2}$ : chemical and structural properties of the carbonized products. Biomass Bioenerg. 35, 3152-3159 (2011)

[16] Falco, C., Baccile, N., Titirici, M.M.: Morphological and structural differences between glucose, cellulose and lignocellulosic biomass derived hydrothermal carbons. Green Chem. 13, 3273-3281 (2011)

[17] Kang, S., Li, X., Fan, J., Chang, J.: Characterization of hydrochars produced by hydrothermal carbonization of lignin, cellulose, D-Xylose, and wood meal. Ind. Eng. Chem. Res. 51, 9023-9031 (2012)

[18] Berge, N.D., Ro, K.S., Mao, J., Flora, J.R.V., Chappell, M.A., Bae, S.: Hydrothermal carbonization of municipal waste streams. Environ. Sci. Technol. 45, 5696-5703 (2011)

[19] Gao, P., Zhou, Y., Meng, F., Zhang, Y., Liu, Z., Zhang, W., Xue, G.: Preparation and characterization of hydrochar from waste eucalyptus bark by hydrothermal carbonization. Energy 97, 238-245 (2016)

[20] Funke, A., Ziegler, F.: Hydrothermal carbonization of biomass: a summary and discussion of chemical mechanisms for process engineering. Biofuel Bioprod. Bior. 4, 160-177 (2010) 
[21] Reza, M.T., Lynam, J.G., Uddin, M.H., Coronella, C.J.: Hydrothermal carbonization: fate of inorganics. Biomass Bioenerg. 49, 86-94 (2013)

[22] Hoekman, S.K., Broch, A., Robbins, C., Zielinska, B., Felix, L.: Hydrothermal carbonization (HTC) of selected woody and herbaceous biomass feedstocks. Biomass Conv. Bioref. 3:113-126 (2012)

[23] Reza, M.T., Uddin, M.H., Lynam, J.G., Hoekman, S.K., Coronella, C.J.: Hydrothermal carbonization of loblolly pine: reaction chemistry and water balance. Biomass Conv. Bioref. 4, 311-321 (2014)

[24] Reza, M.T., Nover, J., Wirth, B., Coronella, C.J.: Hydrothermal carbonization of glucose in saline solution: sequestration of nutrients on carbonaceous materials. AIMS Energy 4, 173-189 (2016).

[25] Antal, M.J., Grønli, M.: The Art, Science, and Technology of Charcoal Production. Ind. Eng. Chem. Res. 42, 1619-40 (2003).

[26] Liu, H-M., Xie, X-A., Li, M-F., Sun, R-C.: Hydrothermal liquefaction of cypress: effects of reaction conditions on 5-lump distribution and composition. J. Anal. Appl. Pyrol. 94, 177-183 (2012)

[27] Saqib, N.U., Oh, M., Jo, W., Park, S.K., Lee J.Y.: Conversion of dry leaves into hydrochar through hydrothermal carbonization (HTC). J. Mater. Cycles Waste Manage. 19, 111-117 (2017)

[28] Parshetti, G.K., Hoekman, S.K., Balasubramanian, R.: Chemical, structural and combustion characteristics of carbonaceous products obtained by hydrothermal carboniza- tion of palm empty fruit bunches. Bioresour. Technol. 135: 683-689 (2013)

[29] Xu, Q., Qian, Q., Quek, A., Ai, N., Zeng, G., Wang, J.: Hydrothermal carbonization of macroalgae and the effects of experimental parameters on the properties of hydrochars. ACS Sustain. Chem. Eng. 1, 1092-1101 (2013)

[30] Liu, Z.G., Quek, A., Hoekman, S.K., Balasubramanian, R.: Production of solid biochar fuel from waste biomass by hydrothermal carbonization. Fuel 103, 943949 (2013) 
[31] Jamari, S.S., Howse, J.R.: The Effect of the hydrothermal carbonization process on palm oil empty fruit bunch. Biomass Bioenerg. 47, 82-90 (2012)

[32] Sevilla, M., Fuertes, A.B.: The production of carbon materials by hydrothermal carbonization of cellulose. Carbon 47, 2281-2289 (2009)

[33] Vassilev, S.V., Baxter, D., Andersen, L.K., Vassileva, C.G., Morgan, TJ.: An overview of the organic and inorganic phase composition of biomass. Fuel 94, 1$33(2012)$

[34] Islam, M.A., Kabir, G., Asif, M., Hameed, BH.: Combustion kinetics of hydrochar produced from hydrothermal carbonisation of Karanj (Pongamia pinnata) fruit hulls via thermogravimetric analysis. Bioresour. Technol. 194, 14$20(2015)$

[35] Haykiri-Acma, H., Yaman, S., Kucukbayrak, S.: Comparison of the thermal reactivities of isolated lignin and holocellulose during pyrolysis. Fuel Process Technol. 91, 759-764 (2010)

[36] Yang, H., Yan, R., Chen, H., Lee, D., Zheng, C.: Characteristics of hemicellulose, cellulose and lignin pyrolysis. Fuel 86, 1781-1788 (2007)

[37] Álvarez-Murillo, A., Ledesma, B., Román, S., Sabio, E., Gañán, J.: Biomass pyrolysis toward hydrocarbonization. Influence on subsequent steam gasification processes. J. Anal. Appl. Pyrol. 113, 380-389 (2015)

[38] Guiotoku, M., Rambo C.R., Hotza, D.: Charcoal produced from cellulosic raw materials by microwave-assisted hydrothermal carbonization. J. Therm. Anal. Calorim. 117, 269-275 (2014)

[39] Sing, K.S.W., Everett, D.H., Haul, R.A.W., Moscou, L., Pierotti, R.A., Rouquerol, J., et al.: Reporting physisorption data for gas/solid systems. Pure Appl. Chem. $57,603-619$ (1985)

[40] Fuertes, A.B., Arbestain, M.C., Sevilla, M., Macial'-Agulloı', J.A., Fiol, S., Loı' pez $\mathrm{R}$, et al.: Chemical and structural properties of carbonaceous products obtained by pyrolysis and hydrothermal carbonisation of corn stover. Aust. J. Soil Res. 48, 618-626 (2010) 
This is a post-peer-review, pre-copyedit version of an article published in Waste and Biomass Valorization.. The final authenticated version is available online at: https://doi.org/10.1007/s12649-018-0209-x

[41] Mochidzuki, K., Sato, N., Sakoda, A.: Production and characterization of carbonaceous adsorbents from biomass wastes by aqueous phase carbonization. Adsorption 11: 669-673 (2005) 
Tables

\begin{tabular}{|c|c|c|c|c|c|c|c|c|c|c|c|}
\hline Materials & C (\%) & H (\%) & N (\%) & $0^{a}(\%)$ & ${ }^{*} \mathbf{O} / \mathrm{C}$ & ${ }^{*} \mathrm{H} / \mathrm{C}$ & pH & $\begin{array}{l}\text { Ash } \\
(\%)\end{array}$ & $\begin{array}{l}\text { HHV } \\
\text { (MJ/Kg) }\end{array}$ & $\begin{array}{l}\text { Energy } \\
\text { densification } \\
\text { ratio }\end{array}$ & $\begin{array}{l}\text { Energy } \\
\text { yield } \\
(\%)\end{array}$ \\
\hline Feedstock & $46.77 \pm 0.03$ & $5.44 \pm 0.01$ & $0.00 \pm 0.00$ & $47.79 \pm 0.04$ & 0.77 & 1.40 & $6.87 \pm 0.01$ & & 15.06 & & \\
\hline $\mathrm{CSH}_{200-30}$ & $54.78 \pm 0.80$ & $5.78 \pm 0.08$ & $0.13 \pm 0.04$ & $39.31 \pm 0.92$ & 0.54 & 1.25 & $4.35 \pm 0.02$ & $18.30 \pm 0.75$ & 19.76 & 1.31 & 85.28 \\
\hline $\mathrm{CSH}_{200-20}$ & $53.84 \pm 0.25$ & $5.31 \pm 0.10$ & $0.00 \pm 0.00$ & $40.85 \pm 0.35$ & 0.57 & 1.17 & $4.36 \pm 0.01$ & $18.12 \pm 0.23$ & 18.50 & 1.23 & 78.64 \\
\hline $\mathrm{CSH}_{200-15}$ & $53.24 \pm 0.45$ & $5.25 \pm 0.03$ & $0.01 \pm 0.00$ & $41.50 \pm 0.48$ & 0.59 & 1.17 & $4.35 \pm 0.00$ & $18.05 \pm 0.93$ & 18.10 & 1.20 & 75.71 \\
\hline $\mathrm{CSH}_{200-10}$ & $52.01 \pm 0.80$ & $5.74 \pm 0.12$ & $0.00 \pm 0.00$ & $42.25 \pm 0.92$ & 0.61 & 1.31 & $4.60 \pm 0.01$ & $17.76 \pm 0.10$ & 18.25 & 1.21 & 75.74 \\
\hline $\mathrm{CSH}_{200-5}$ & $51.55 \pm 0.69$ & $5.87 \pm 0.30$ & $0.00 \pm 0.00$ & $42.58 \pm 0.99$ & 0.63 & 1.33 & $4.88 \pm 0.00$ & $15.24 \pm 1.02$ & 18.22 & 1.21 & 73.79 \\
\hline $\mathrm{CSH}_{170-20}$ & $52.36 \pm 0.97$ & $5.69 \pm 0.23$ & $0.00 \pm 0.00$ & $41.95 \pm 1.20$ & 0.60 & 1.29 & $4.90 \pm 0.02$ & $15.15 \pm 0.92$ & 18.35 & 1.22 & 75.52 \\
\hline $\mathrm{CSH}_{150-20}$ & $49.92 \pm 0.85$ & $5.53 \pm 0.13$ & $0.03 \pm 0.01$ & $44.92 \pm 0.99$ & 0.67 & 1.33 & $5.26 \pm 0.01$ & $14.33 \pm 1.10$ & 16.77 & 1.11 & 64.58 \\
\hline
\end{tabular}

a Oxygen content was determined by difference $[100 \%-(\mathrm{C} \%+\mathrm{H} \%+\mathrm{N} \%)][4,6,7]$

* Atomic ratio

Table 1: Elemental analysis, $\mathrm{pH}$, ash contents and energy properties of the feedstock and the hydrochars.

\begin{tabular}{|c|c|c|c|}
\hline Section & Wavelength range (cm-1) & Functional group & Description \\
\hline 1 & $3600-3000$ & O-H stretching & Broad peak due to water and alcohols from cellulose, or phenols from lignin. \\
\hline 2 & $3000-2800$ & C-H stretching & Double peaks due to the stretching vibrations of aliphatic $\mathrm{C}-\mathrm{H}$ bond. \\
\hline 3 & $1800-1650$ & $\mathrm{C}=\mathrm{O}$ stretching & $\begin{array}{l}\text { Vibrations of esters, carboxylic acids or aldehydes present in the cellulose and } \\
\text { lignin. }\end{array}$ \\
\hline 4 & $1650-1500$ & $\mathrm{C}=\mathrm{C}$ stretching & Vibration due to the aromatic rings in lignin. \\
\hline 5 & $1450-1200$ & $\mathrm{C}-\mathrm{H}$ bending & $\begin{array}{l}\text { Peaks due to the absorption from } \mathrm{CH} \text { bond of aliphatic carbons, methylene, and } \\
\text { methyl groups. }\end{array}$ \\
\hline 6 & $1200-950$ & C-O stretching & Due to vibration from phenols, esters, and aliphatic alcohols. \\
\hline 7 & $<950$ & C-H bending & Resulting from the deformation of the $\mathrm{CH}$ bond in aromatic compounds. \\
\hline
\end{tabular}

Table 2: Allocation of functional groups to FTIR peaks of the feedstock and the hydrochar 


\section{Figures}

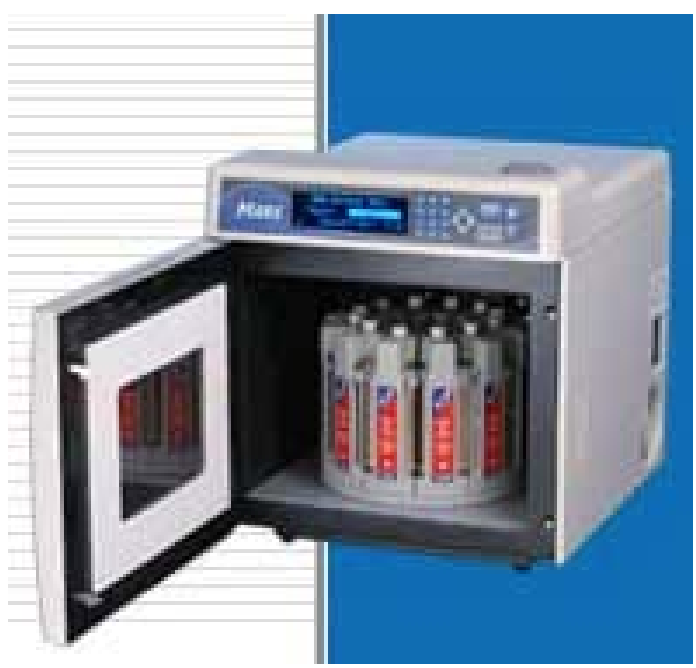

Fig. 1 Microwave oven (MARS, CEM) with the pressurized XP1500 digestion vessels used for experiment. Figure used with permission for reproduction obtained from Elsevier [License Number: 4197200736298].

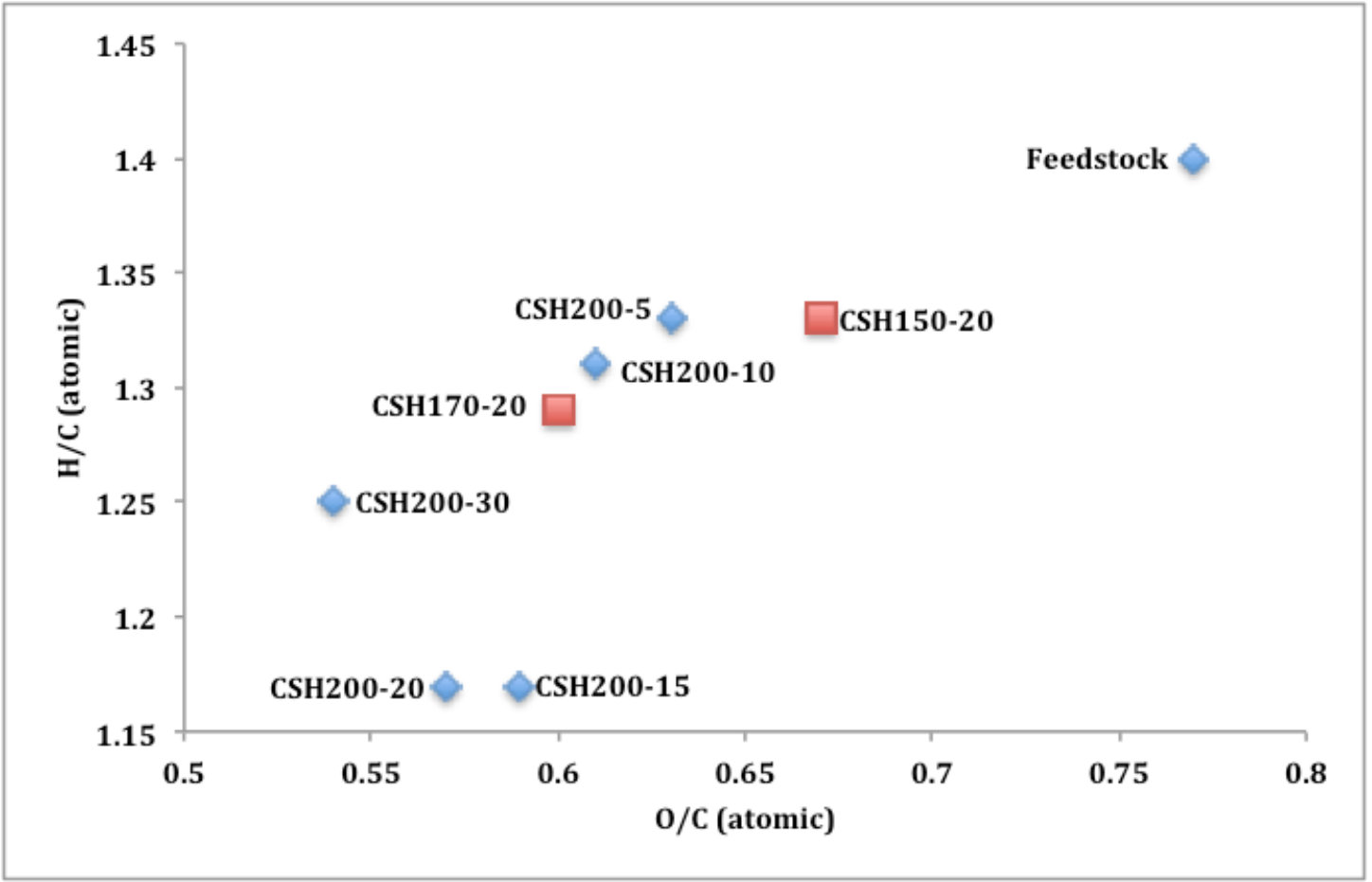

Fig. 2: van Krevelen diagram of the feedstock and the hydrochars 


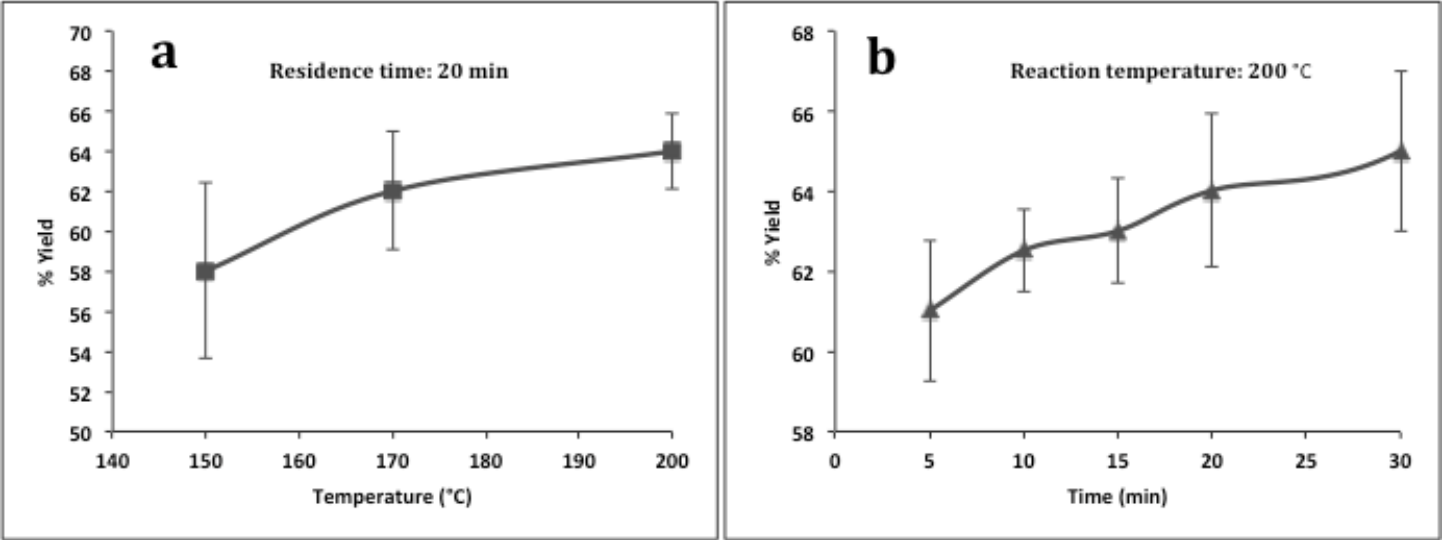

Fig. 3: Effect of (a) reaction temperature, (b) residence time on the product yields of the hydrochars.

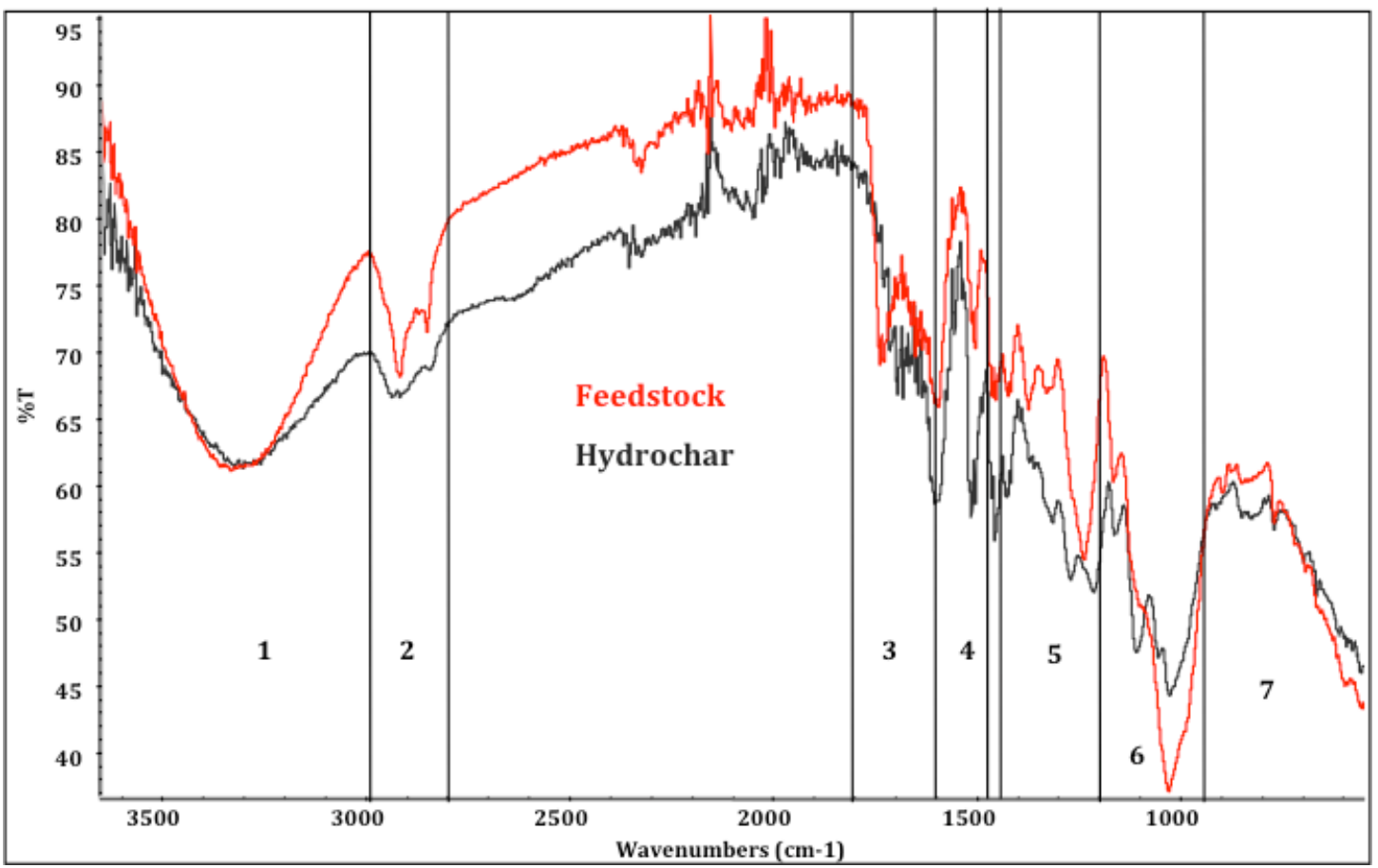

Fig. 4: FTIR spectra of the feedstock and hydrochar showing the different sections of wavelengths for the functional groups present 


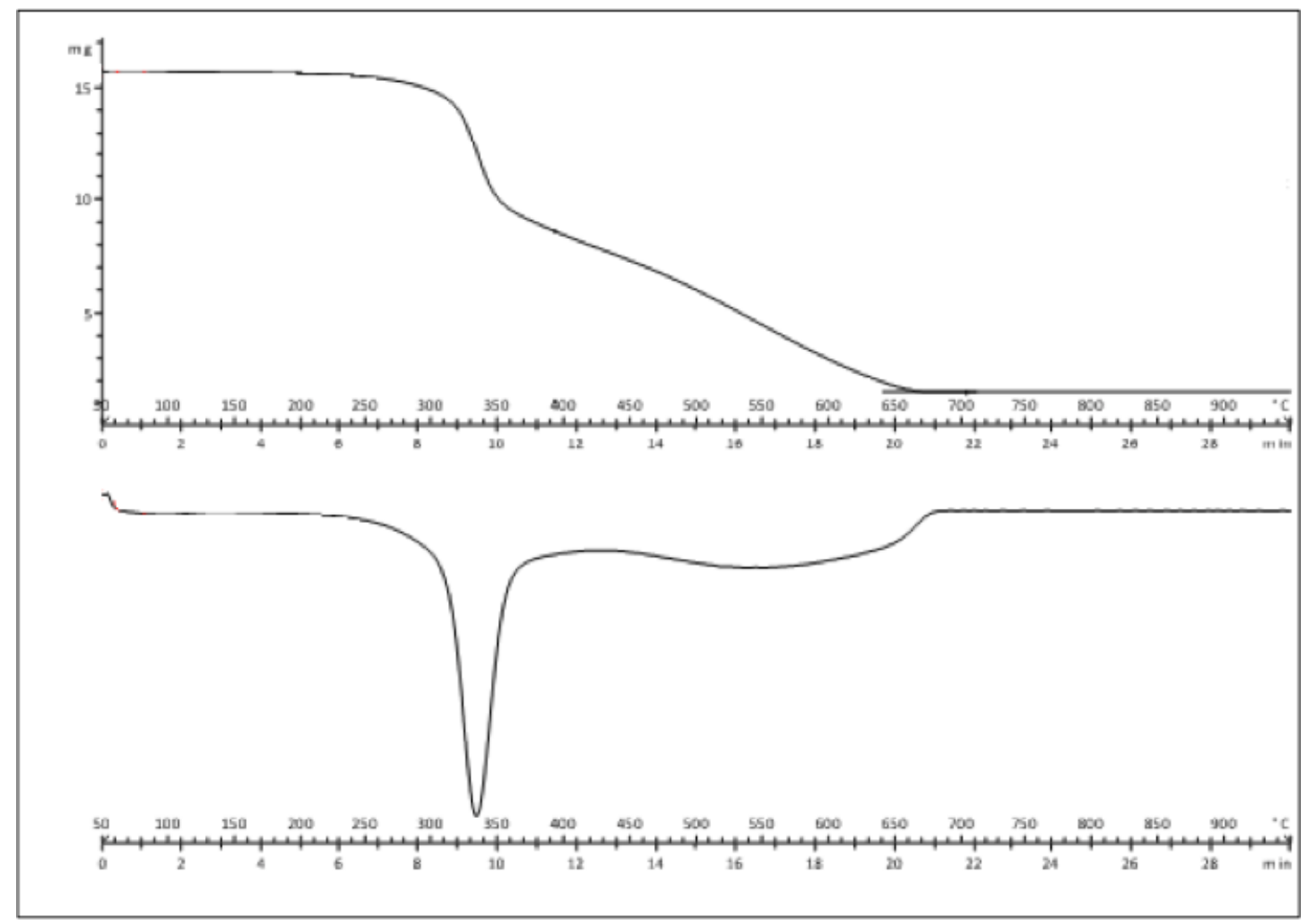

Fig. 5: TGA and DTG profiles of the hydrochar
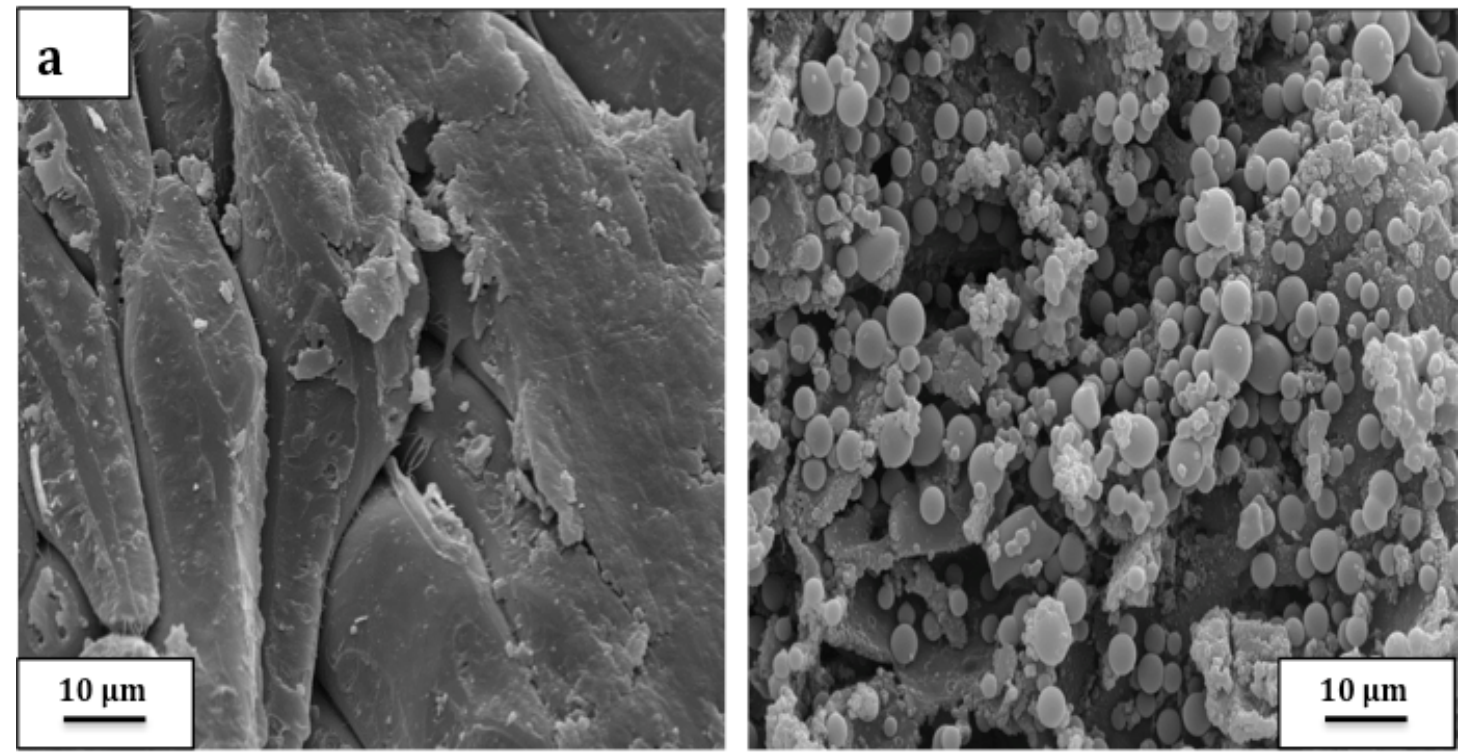

Fig. 6: SEM images of (a) feedstock, (b) hydrochar 


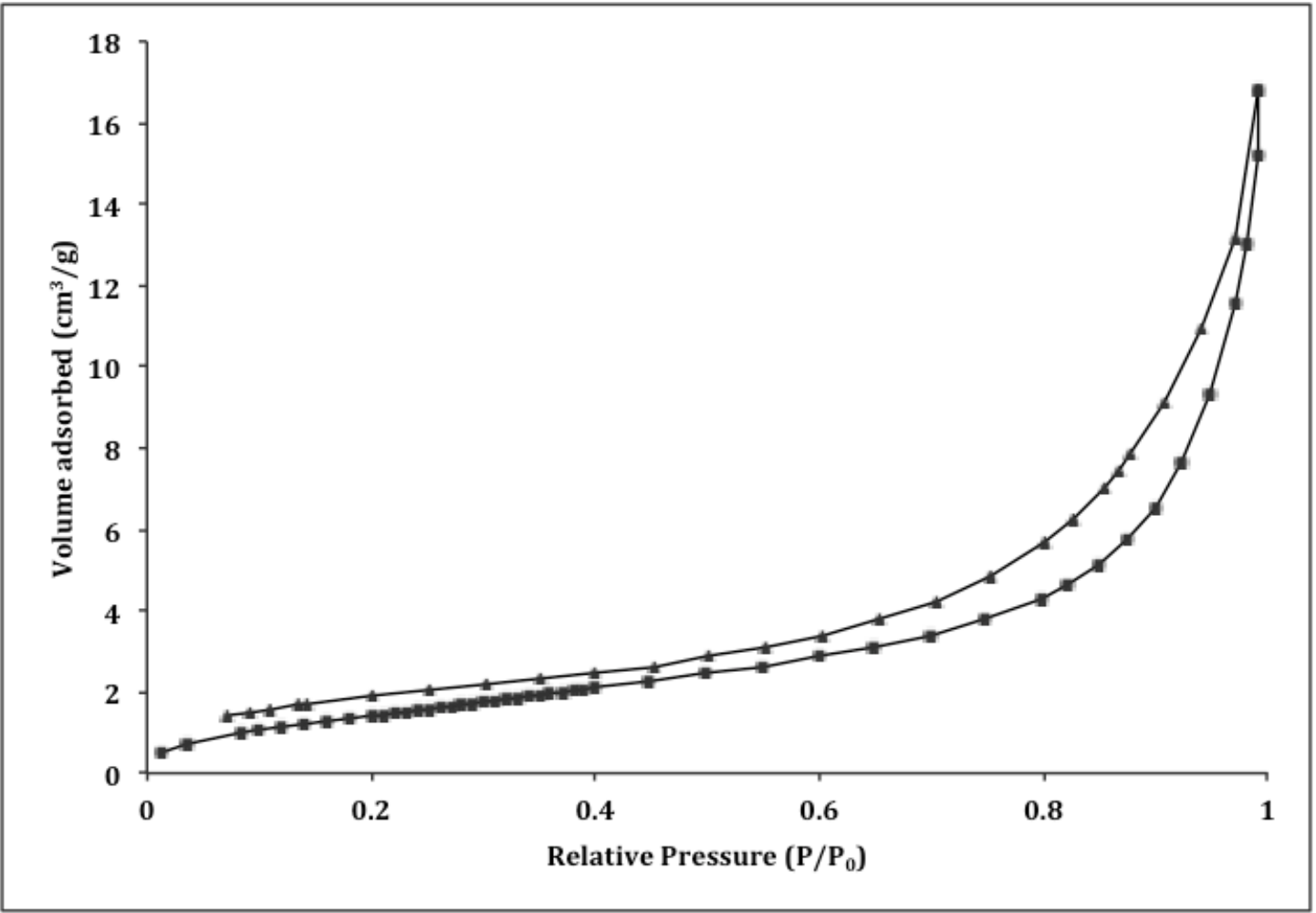

Fig. 7: Nitrogen adsorption isotherm of the hydrochar 